\title{
Appendiceal bleeding in an elderly male: a case report and a review of the literature
}

\author{
Yuto Maeda ${ }^{1,2 *}$, Seiya Saito², Mayuko Ohuchi², Yuka Tamaoki², Jiro Nasu² and Hideo Baba ${ }^{1}$
}

\begin{abstract}
Background: The prevalence of acute lower gastrointestinal bleeding has been increased including colonic diverticulitis and angioplasty. However, appendiceal bleeding is extremely rare.

Case presentation: We present a case of lower gastrointestinal bleeding from the appendix in an elderly male who presented with melena. Appendiceal bleeding was diagnosed using lower gastrointestinal endoscopy, and laparoscopic appendectomy was performed. The patient did not have melena postoperatively, and was discharged 6 days after the surgery.
\end{abstract}

Conclusion: It is important to distinguish appendiceal bleeding from lower gastrointestinal bleeding and to treat it as soon as possible with less invasiveness.

Keywords: Lower gastrointestinal bleeding, Appendix bleeding, Appendectomy

\section{Background}

Acute lower gastrointestinal bleeding has been increased, including colonic diverticulitis and angioplasty [1-3]. However, the source of appendix bleeding is very rare. We have experienced a case in which the source of lower gastrointestinal bleeding was the appendix in an elderly male. Here, we present a case studies to treat appendiceal bleeding, and we report it with some review of the literature.

\section{Case presentation}

A 90-year-old man presented to our hospital with melena that lasted for about 2 days. There were no signs of hematochezia. No gastrointestinal symptoms such as abdominal pain were observed. He had no apparent family history of colorectal cancer. He had been diagnosed with hypertension, benign prostatic hyperplasia, and atrial fibrillation, and was taking bayaspirin for atrial

\footnotetext{
*Correspondence: mm100035.cis.0814@gmail.com

1 Department of Gastroenterological Surgery, Graduate School of Medical Sciences, Kumamoto University, 1-1-1 Honjo, Chuo-ku, Kumamoto 860-8556, Japan

Full list of author information is available at the end of the article
}

fibrillation. The patient had no fever or abdominal pain, and his conjunctivae were not pale. Nevertheless, a digital rectal examination showed blood clot at the time of consultation at our hospital. On admission, laboratory evaluation revealed anemia with hemoglobin of $11.9 \mathrm{~g} / \mathrm{dl}$ and a hematocrit of $34.9 \%$. Lower gastrointestinal endoscopy was performed, but the cause of the bleeding could not be identified. However, 1 day following admission, he passed dark stools again. One day later, his hemoglobin level dropped from $11.9 \mathrm{~g} / \mathrm{dl}$ to $10.4 \mathrm{~g} / \mathrm{dl}$; therefore, an emergency lower gastrointestinal endoscopy was performed. This showed that bright red blood was oozing out of the appendix. Immediately after washing out the blood, appendiceal bleeding was evident (Fig. 1). Next, laparoscopic appendectomy was performed. During the surgery, the appendix was $70 \times 5 \mathrm{~mm}$ in size and there were no inflammatory changes or adhesions seen in the appendix. No abnormalities were observed on the mucosal surface; however, bleeding was observed from the appendiceal wall. On histopathology, we observed a couple of bleeding point into the submucosa, but diverticula or neoplastic lesions that may have caused the appendical bleeding were not found (Fig. 2). One day 


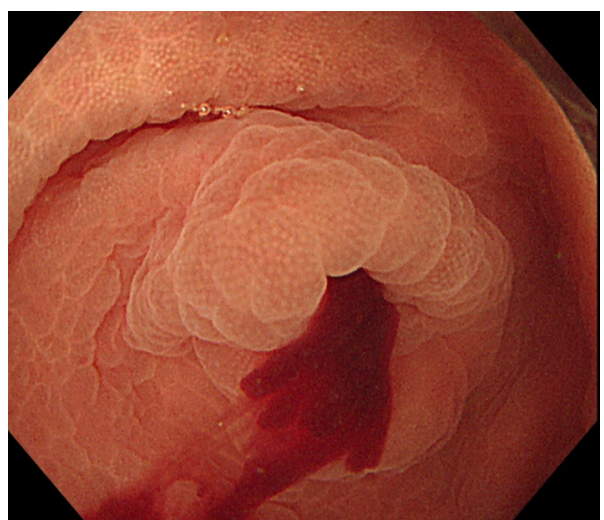

Fig. 1 Lower gastrointestinal endoscopic findings. Bleeding is observed from the appendiceal orifice

following surgery, no melena was observed and the patient was discharged from the hospital 6 days after the surgery.

\section{Discussion}

Lower gastrointestinal bleeding is a common cause of hospitalization. Patients with lower gastrointestinal bleeding usually require a blood transfusion and interventions, such as gastrointestinal endoscopy and surgical treatment. Common causes of lower gastrointestinal bleeding include diverticulum bleeding, ischemic colitis, angioectasia, and post-polypectomy bleeding. Other less common causes include rectal ulcerative colitis, infectious colitis, inflammatory bowel disease, colorectal polyps / neoplasms, radiation proctitis, and hemorrhoids. However, the bleeding from the appendix is a very rare cause of lower gastrointestinal bleeding [4, 5]. This is despite the fact that the same factors that are responsible for lower gastrointestinal bleeding (i.e., inflammation, angiodysplasia, diverticulum, granulomatous appendicitis, tumor and damage of the appendix mucosa) can also cause appendiceal bleeding [6-8]; however, the cause of appendiceal bleeding may not be identified. A search on PubMed/MEDLINE database for literature published between January 1977 and August 2020 regarding "appendix bleeding" or "appendix hemorrhage" identified 30 articles [9-36] (Table 1). The average age of cases of appendiceal bleeding was 46.6 years (14-90 years). Our case was diagnosed at the oldest age among the cases, and the treatment was effective.

The pathological findings in our case showed a couple of bleeding points into the submucosa, but no abnormality was observed on the mucosal surface. Furthermore, multiple diverticula or arterial wall rupture, which are thought to be the cause of appendiceal bleeding, were not found. Hence, pathological findings caused unknown of appendiceal bleeding.

In previous some reports, not only endoscopy but also CT examinations are performed for diagnosis [9-36]. However, most of the definitive diagnosis were endoscopic findings of bleeding from the appendiceal orifice. In this case as well, a definitive diagnosis could be obtained by endoscopic findings, as in previous reports. Therefore, the operation was performed as soon as possible without adding CT examination.

Although emergency surgery such as laparoscopic appendectomy or laparoscopic ileocecal resection is usually performed as a treatment, a strategy for appendiceal bleeding has not been established. Other treatment for appendical bleeding has been reported including arterial embolization, therapeutic barium enema, and clipping $[16,22,36]$. On the other hand, the risk of severe appendicitis, perforation and rebleeding from these treatments has been reported [37]. Therefore, surgery as a definitive
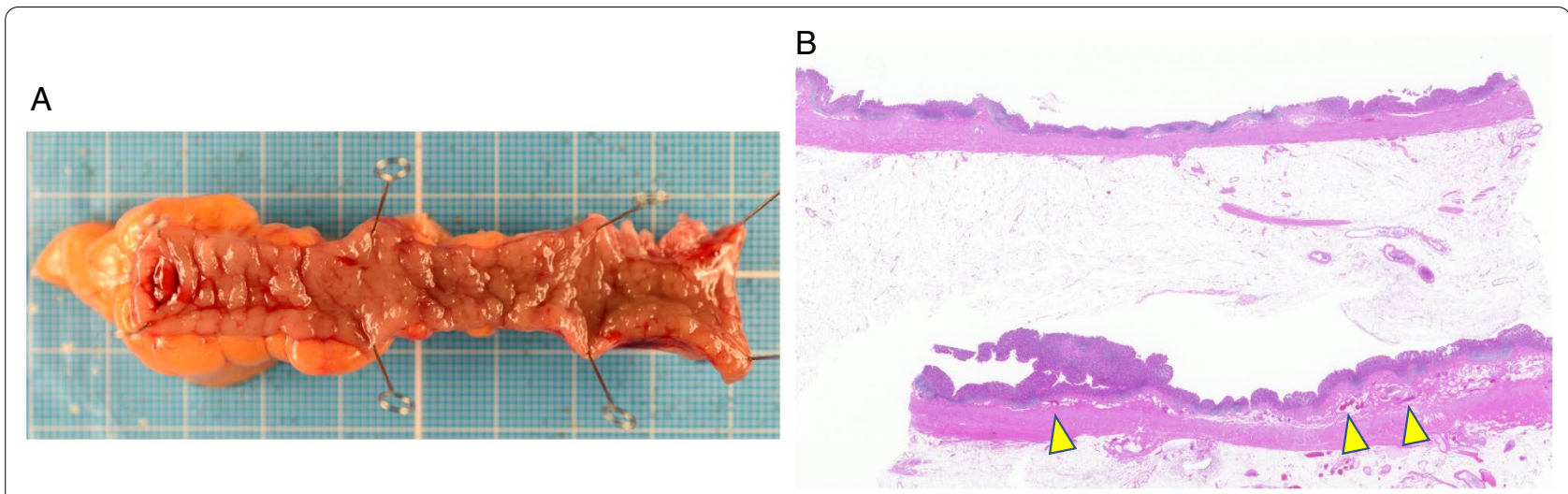

Fig. 2 Excised specimen, histopathological findings. a Appendix is $70 \times 5 \mathrm{~mm}$ in size. No abnormalities were observed on the mucosal surface. $\mathbf{b}$ Pathological findings showed a couple of bleeding points into the submucosa (arrow head), but no rupture of the arterial wall or abnormalities on the mucosal surface were observed 


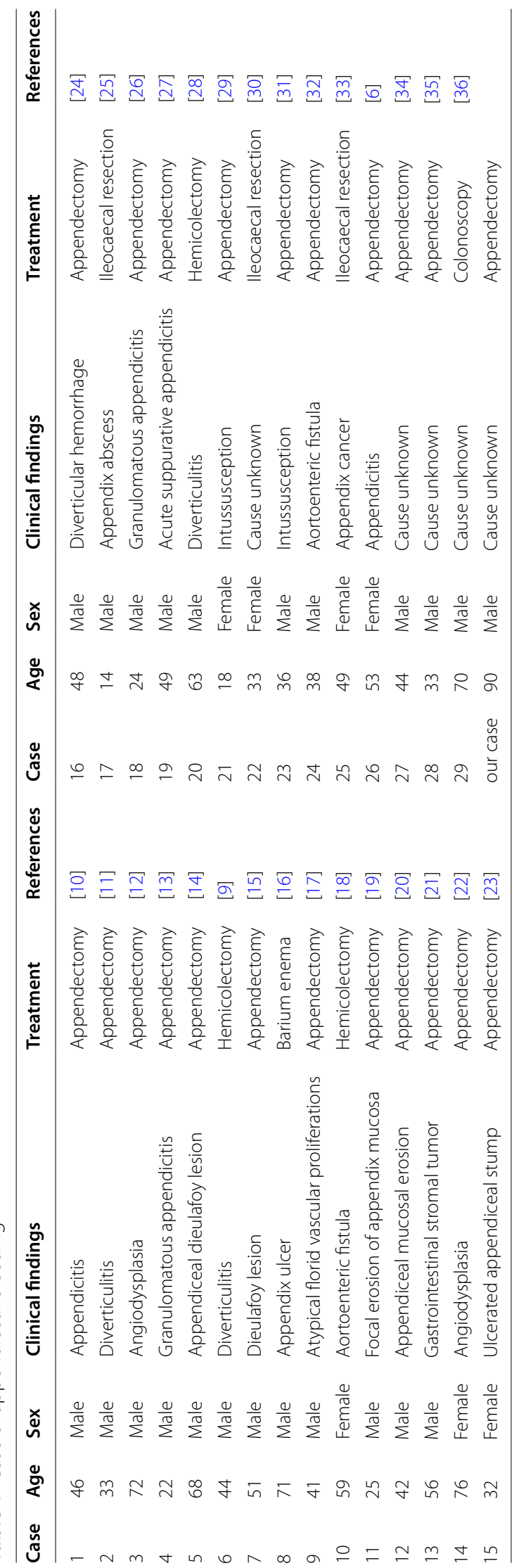


treatment were performed in many cases, consecutively. In this case, although he was very eldery, we decided that laparoscopic surgery was more appropriate because of its tolerability and curability of treatment. Treatments for appendiceal bleeding should be considered as early as possible, with less invasiveness, but further research regarding its safety and complication associated with the procedure should be conducted in the future.

\section{Conclusions}

We present a case of appendiceal bleeding in an elderly male patient. It is important to distinguish appendiceal bleeding from lower gastrointestinal bleeding and to treat it as soon as possible with less invasiveness.

\section{Acknowledgements}

Not applicable.

\section{Authors' contributions}

$\mathrm{ON}, \mathrm{JN}$ and HB collected, analyzed, and interpreted the data and revised the manuscript. All authors read and approved the final manuscript.

\section{Funding}

This research received no specific grant from any funding agency in the public, commercial, or not-for-profit sectors.

\section{Availability of data and materials}

Not applicable.

\section{Declarations}

\section{Ethics approval and consent to participate}

This study was carried out in accordance with the principles of the Declaration of Helsinki.

\section{Consent for publication}

Written informed consent was obtained from the patient for publication of this case report and any accompanying images.

\section{Competing interests}

The authors declare no conflicts of interest.

\section{Author details}

${ }^{1}$ Department of Gastroenterological Surgery, Graduate School of Medical Sciences, Kumamoto University, 1-1-1 Honjo, Chuo-ku, Kumamoto 860-8556, Japan. ${ }^{2}$ Department of Surgery, Kumamoto Chuo Hospital, 1-5-1 Tainoshima, Minami-ku, Kumamoto 862-0965, Japan.

Received: 26 March 2021 Accepted: 9 June 2021

Published online: 23 June 2021

\section{References}

1. Lanas A, García-Rodríguez LA, Polo-Tomás M, Ponce M, Alonso-Abreu I, Perez-Aisa MA, et al. Time trends and impact of upper and lower gastrointestinal bleeding and perforation in clinical practice. Am J Gastroenterol. 2009; 104:1633-41.

2. Lanas A, García-Rodríguez LA, Polo-Tomás M, Ponce M, et al. The changing face of hospitalisation due to gastrointestinal bleeding and perforation. Aliment Pharmacol Ther. 2011;33:585-91.

3. Nagata N, Niikura R, Aoki T, Shimbo T, Itoh T, et al. Increase in colonic diverticulosis and diverticular hemorrhage in an aging society: lessons from a 9-year colonoscopic study of 28,192 patients in Japan. Int J Colorectal. 2014:8:78.
4. Tomonori A, Yoshihiro $\mathrm{H}$, Atsuo Y, et al. Initial management for acute lower gastrointestinal bleeding. J Gastroenterol. 2019;25(1):69-84.

5. Strate LL. Gralnek IM. ACG clinical guideline: management of patients with acute lower gastrointestinal bleeding. Am J Gastroenterol. 2016;111:459-74.

6. Yamazaki K, Nakao K, Tsunoda A, et al. Successful laparoscopic treatment of hemorrhage from the appendix with phlegmonous acute appendicitis: a case report and review of the literature. Gastrointest Endosc. 2006;63:877-80.

7. Holtz LR, Neill MA, Tarr PI. Acute bloody diarrhea: a medical emergency for patients of all ages. Gastroenterology. 2009;136:1887-98.

8. AbdullGaffar B. Granulomatous diseases and granulomas of the appendix. Int J Surg Pathol. 2010;18:14-20.

9. Vesa TS, Hosseini-Carroll P, Manas K. Diverticular hemorrhage of the appendix. Gastroenterol Hepatol (NY). 2014;10:394-5.

10. Shen Z, Huang YZ, Ning LM, Gao HC, Wang W. A case of lower digestive tract hemorrhage caused by appendicitis in China. Int J Surg Case Rep. 2017;39:34-5.

11. Ur Rehman M, Paulus F, Chew MH. Unexpected histopathology of acute appendicitis. Int J Surg Case Rep. 2017;38:23-5.

12. Choi JM, Lee SH, Lee SH, Ahn BK, Baek SU. Hematochezia due to angiodysplasia of the appendix. Ann Coloprocto. 2016;32:117-9.

13. Magaz Martinez M, Martin Lopez J, Dela Revilla Negro J, Gonzalez Partida I, Las Heras T, Sanchez Yuste MR. Appendicular bleeding: an excepcional cause of lower hemorrhage. Rev Esp Enferm. 2016;108:7.

14. Reynolds JK, Mejia VA. Appendiceal Dieulafoy lesion: an unusual cause of massive lower gastrointestinal bleeding. Am Surg. 2015;81:E18-9.

15. Johnson A, Oger M, Capovilla M. Dieulafoy lesion of the appendix. Dig Liver Dis. 2014;46:e11.

16. Konno Y, Fujiya M, Tanaka K, Sakatani A, Shimoda M, Hayashi A. A therapeutic barium enema is a practical option to control bleeding from the appendix. BMC Gastroenterol. 2013;13:78.

17. Gu MJ, Choi JH, Kim SH. Atypical florid vascular proliferation in appendix: a diagnostic dilemma. Diagn Pathol. 2013;8:12.

18. Monjero-Ares I, Gegundez-Gomez C, Rielo-Arias FJ, Alvarez-Gutierrez AE, Pena-Holguin J, Alvite-Canosa M. Iliac-appendiceal fistula. An unusual cause of gastrointestinal bleeding. Rev Esp Enferm Dig. 2012;104:387-8.

19. Chiang CC, Tu CW, Liao CS, Shieh MC, Sung TC. Appendiceal hemorrhage - an uncommon cause of lower gastrointestinal bleeding. J Chin Med Assoc. 2011;74:277-9.

20. Baek SK, Kim YH, Kim SP. Acute lower gastrointestinal bleeding due to appendiceal mucosal erosion. Surg Laparosc Endosc Percutan Tech. 2010;20:E110-3.

21. Kim KJ, Moon W, Park MI, Park SJ, Lee SH, Chun BK. Gastrointestinal stromal tumor of appendix incidentally diagnosed by appendiceal hemorrhage. World J Gastroenterol. 2007;13:3265-7.

22. Kyokane T, Akita Y, Katayama M, Kitagawa Y, Sato T, Shichino S. Angiodysplasia of the appendix. Am J Gastroenterol. 2001;96:242-4.

23. Choi DY, Yuh JN, Reid JD. Rectal hemorrhage from ulcerated appendiceal stump nine years after appendectomy. Report of a case. Dis Colon Rectum. 1985;28:454-6.

24. Norman DA, Morrison EB, Meyers WM. Massive gastrointestinal hemorrhage from a diverticulum of the appendix. Dig Dis Sci. 1980;25:145-7.

25. Milewski PJ. Appendix abscess with intestinal haemorrhage. Br Med J. 1977;1:147.

26. Chen W, Qiu H, Zhang J. Appendix bleeding with painless bloody diarrhea: a case report and literature review. Open Med. 2019;14:735-9.

27. Dae-ha K, JuHan L, Dongwoo K, Suhyun H, Kyuho K, Ja S. Acute suppurative appendicitis diagnosed by acute lower gastrointestinal hemorrhage Korean. J Gastroenterol. 2016;73:45-9.

28. Mullen JT. Mucocele of the appendix associated with hematochezia. South Med J. 1979;72:766-77.

29. Mclntosh JC, Mroczek EC, Baldwin C, et al. Intussusception of the appendix in a patient with cystic fibrosis. J Pediatr Gastroenterol Nutr. 1990;11:542-4

30. Shome GP, Nagaraju M, Munis A, et al. Appendicecal endometoriosis presenting as massive lower intestinal hemorrhage. Am J Gastroenterol. 1995:90:1881-3.

31. Gupta P, Chwals W. Guandalini S : Intussusception of the appendix: another poorly recognized cause of rectal bleeding. J Pediatr Gastroenterol Nutr. 2000:30:320-3. 
32. Monaghan K, Cogbill TH. Primary aortoappendiceal fistula: case report and review of the literature. J Vasc Surg. 2002;35:1284-6.

33. Takahashi M, Sawada T, Fukuda T. Complete appendiceal intussusception induced by primary appendiceal adenocarcinoma in tubular adenoma: a case report. Jpn J Clin Oncol. 2003;33:413-5.

34. Park I, Kwon $\mathrm{Cl}$, Ko KH, et al. Colonoscopic clipping as a treatment for appendiceal bleeding. Gut Liver. 2010;4:411-4.

35. Chung KS, Gao JP. Massive lower gastrointestinal bleeding from the appendix. Gut Liver. 2011:5:234-7.

36. IlHyung C, Kwang HK. A case of successful colonoscopic treatment of acute appendiceal bleeding by endoclips. J Korean Soc Coloproctol. 2011;27:329-32.
37. Jensen DM, Ohning GV, Kovacs TO, et al. Natural history of definitive diverticular hemorrhage based on stigmata of recent hemorrhage and colonoscopic Doppler blood flow monitoring for risk stratification and definitive hemostasis. Gastrointest Endosc. 2016;83:416-23.

\section{Publisher's Note}

Springer Nature remains neutral with regard to jurisdictional claims in published maps and institutional affiliations.

\section{Submit your manuscript to a SpringerOpen ${ }^{\circ}$ journal and benefit from:}

- Convenient online submission

- Rigorous peer review

- Open access: articles freely available online

- High visibility within the field

- Retaining the copyright to your article

Submit your next manuscript at $\boldsymbol{\nabla}$ springeropen.com 